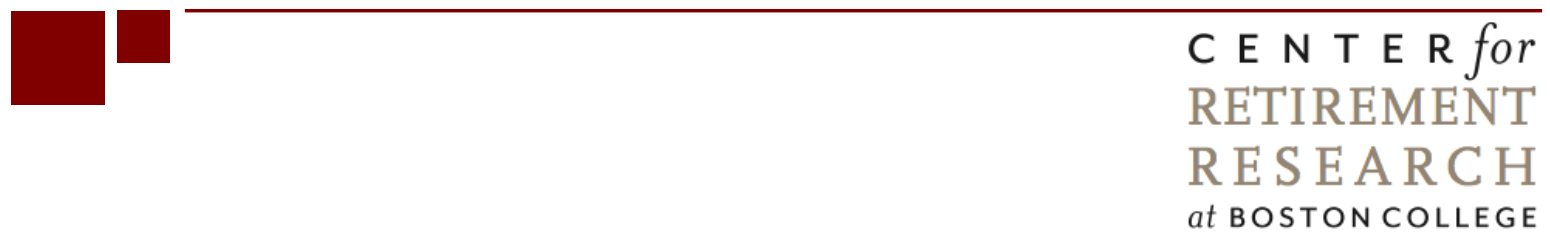

\title{
RETHINKING OPTIMAL WEALTH ACCUMULATION AND DECUMULATION STRATEGIES IN THE WAKE OF THE FINANCIAL CRISIS
}

\author{
Richard W. Kopcke, Anthony Webb, Josh Hurwitz, and Zhenyu Li
}

CRR WP 2013-1

Submitted: December 2012

Released: January 2013

\author{
Center for Retirement Research at Boston College \\ Hovey House \\ 140 Commonwealth Avenue \\ Chestnut Hill, MA 02467 \\ Tel: 617-552-1762 Fax: 617-552-0191 \\ http://crr.bc.edu
}

\begin{abstract}
All the authors are with the Center for Retirement Research at Boston College. Richard W. Kopcke is a research consultant, Anthony Webb is a research economist, and Josh Hurwitz and Zhenyu Li are research associates. The research reported herein was pursuant to a grant from the U.S. Social Security Administration (SSA), funded as part of the Retirement Research Consortium (RRC). The findings and conclusions expressed are solely those of the authors and do not represent the views of SSA, any agency of the federal government, the RRC, or Boston College.

(c) 2013, Richard W. Kopcke, Anthony Webb, Josh Hurwitz, and Zhenyu Li. All rights reserved. Short sections of text, not to exceed two paragraphs, may be quoted without explicit permission provided that full credit, including (C) notice, is given to the source.
\end{abstract}




\section{About the Center for Retirement Research}

The Center for Retirement Research at Boston College, part of a consortium that includes parallel centers at the University of Michigan and the National Bureau of Economic Research, was established in 1998 through a grant from the Social Security Administration. The Center's mission is to produce first-class research and forge a strong link between the academic community and decision-makers in the public and private sectors around an issue of critical importance to the nation's future. To achieve this mission, the Center sponsors a wide variety of research projects, transmits new findings to a broad audience, trains new scholars, and broadens access to valuable data sources.

Center for Retirement Research at Boston College

Hovey House

140 Commonwealth Avenue

Chestnut Hill, MA 02467

phone: 617-552-1762 fax: 617-552-0191

e-mail: crr@bc.edu

crr.bc.edu

Affiliated Institutions:

The Brookings Institution

Massachusetts Institute of Technology

Syracuse University

Urban Institute 


\begin{abstract}
A substantial literature has developed models of optimal consumption and asset allocation based on the assumption that stocks and bonds have fixed returns, with normal independent, identically distributed disturbances. Households optimally rebalance from stocks to bonds as they age, reflecting the declining proportion of their wealth that is represented by lowrisk human capital.

Using annual return data for large-capitalization stocks and corporate bonds covering the period 1926 through 2011, the paper calculates optimal consumption and asset allocation over the life cycle for a household with Social Security benefits and uncertain labor market earnings. It considers the alternative assumptions that stock and bond returns 1) are normally distributed, 2) follow a vector autoregressive path (VAR) with normally distributed disturbances, and 3) follow a VAR with disturbances drawn from a stable distribution. The assumptions have a significant effect on asset allocation. At age 65, the optimal stock allocation is 52 percent, 68 percent, and 55 percent, respectively, for the three alternatives. When returns follow a VAR with stable disturbances, a household with a constant relative risk aversion (CRRA), assuming a coefficient of risk aversion of 2 would require a 1 percent increase in lifetime consumption to compensate it for assuming that the disturbances to returns follow a normal distribution. Households with a coefficient of risk aversion of 5 would require less than 0.1 percent, reflecting their lower accumulation of wealth and smaller stock allocations.
\end{abstract}




\section{Introduction}

In the U.S. private sector, 401(k) and other defined contribution pension plans have displaced defined benefit plans as the dominant form of pension provision. Workers are responsible for building and investing the savings in their pension funds. Early findings in the theory of life-cycle consumption and portfolio theory suggested that workers would maintain a relatively fixed allocation of assets, depending on their tolerance for bearing risk. Subsequent research, however, concludes that life-cycle savers should rebalance their assets from stocks to bonds as they age, reflecting the declining value of their low-risk human capital.

The substantial literature analyzing models of asset allocation, optimal wealth accumulation, decumulation, and annuitization invariably assumes that stocks are normally distributed. However, considerable research also suggests that the distributions of returns are not stationary from year to year. Returns appear to oscillate around their long-run averages in persistent waves. Research also suggests that the distribution of returns, particularly for stocks, has fat tails and might be skewed. Relatively little research examines the consequences of allowing for time-varying, fat-tailed returns on the household's optimal allocation of assets. ${ }^{1}$ It also suggests that more realistic assumptions about the distribution of returns could alter the optimal allocation of assets significantly.

This paper calculates the optimal consumption and allocation of assets for a risk-averse household that does not know its future labor-market earnings and life span and depends on its Social Security benefits and accumulated wealth to provide income in retirement. We compare the household's optimal expected consumption and allocation of assets for three different assumptions about the distribution of the returns on stocks and bonds. We also calculate the compensation the household would require for being assigned, by mistake, the choices that are optimal for stationary normal returns or for returns that follow a VAR model with normally distributed disturbances, when in fact returns are neither stationary nor normal.

This paper finds that the optimal allocation of assets and the optimal rate of saving are sensitive to the assumptions regarding the distribution of returns on assets. When returns follow a VAR, with disturbances drawn from a stable distribution, a household with a constant relative

\footnotetext{
${ }^{1}$ Notable exceptions include Xiong and Idzorek (2011). This lack of analysis partly reflects the computational difficulty of the task. The literature on optimal wealth accumulation and decumulation uses numerical optimization techniques. This involves discretizing return distributions. The number of discretization points is limited, and it is therefore difficult to capture the tails of the distribution.
} 
risk aversion (CRRA), with a coefficient of risk aversion of 2 that incorrectly assumes that returns are normally distributed with a constant mean, would require an approximately 1 percent increase in per-period consumption to be as well-off in expected utility terms as one with correct beliefs. For a household with a coefficient of risk aversion of 5 , the required compensation is less than 0.1 percent, reflecting the much lower accumulation of wealth and the lower allocation of assets to stocks by risk-averse households.

The remainder of this paper is as follows. Section 1 reviews the literature on optimal asset allocation and on the distributions of returns on stocks and bonds. Section 2 presents the distributions of returns on stocks and bonds used in our analysis. Section 3 presents our model and the optimal choices for expected consumption and allocation of assets for our alternative distributions of the returns on stocks and bonds. Section 4 concludes.

\section{Previous literature}

Returns on risky assets frequently are regarded as random walks, modeled as a fixed return plus normal, independent, identically distributed disturbances (Malkiel 2003; Campbell, Lo and MacKinlay 1997). In these circumstances, some commentators have suggested that risky assets, particularly stocks, are suitable investments for retirement savings because, over many years, the volatility of average returns will be small compared with the volatility of one year's return. ${ }^{2}$ Samuelson (1969) showed that this reasoning, in defense of "time diversification," is misleading. Although the volatility of average returns falls, the volatility of wealth increases with longer holding periods, making stocks no less risky over the long run. ${ }^{3}$ Consequently, in the absence of other income, savers' allocations of assets to stocks seemingly would not vary with their investment horizons or ages.

When savers’ financial resources include human capital as well as financial assets, Bodie, Merton and Samuelson (1992) observed that savers should reduce the allocation of their assets to stocks as they age. Otherwise, savers would expose themselves to more risk as the composition of their financial resources shifts away from relatively secure human capital toward relatively

\footnotetext{
${ }^{2}$ For example, the Securities and Exchange Commission argues that riskier investments are more appropriate for investors with long time-horizons,

${ }^{3}$ When returns are compounded over many years, small variations in the average return become large variations in the value of wealth. Although the calculation of the average annual return compresses the variation in the total return, the compounding of the average return (which is required to derive the distribution of wealth) undoes this compression.
} 
risky stocks. Assuming that the returns on stocks follow a fixed, normal distribution, Jagannathan and Kocherlakota (1996) show that life-cycle savers should consistently rebalance their assets from stocks to bonds as they age (Poterba et al. 2006). A substantial literature calculates the optimal allocation of assets for life-cycle savers, assuming that returns are normally distributed random walks with constant mean and standard deviation (Horneff, Maurer, Mitchell, and Dus, (2006); Horneff, Maurer, Mitchell, and Stamos (2009).

The normal distribution appears to possess a theoretical justification. The distribution of returns on stocks and bonds depend on many factors, including global macroeconomic variables and domestic variables, ranging from monetary and fiscal policy to unemployment and inflation, and from productivity to companies’ profits. Analyses of the returns on assets, assuming efficient markets, typically regard the net effect of these other variables as random disturbances (Campbell, Lo and MacKinlay 1997). According to the Central Limit Theorem, the distribution of the sum of a large number of independent random variables approaches a normal distribution, provided the variables have finite variances and meet various conditions (Rice 1995).

Nonetheless, observers have long questioned the idea that returns are normally distributed random walks. The returns on stocks exhibit high peaks and fat tails, while also showing a tendency to run above or below their long-run averages for long periods (Mandelbrot 1963; Fama 1963; Mandelbrot and Taylor 1967; Shiller 1981; Campbell and Shiller 1998; Xiong and Idzorek 2011; Rachev et al. 2011). From experience, practitioners in financial markets typically do not model returns with stationary normal distributions (Taleb 1997; Gatheral 2006).

These findings endorse distributions of returns that are not stationary, independent, or even normal, and the Generalized Central Limit Theorem provides grounds for a wider family of distributions for the returns on assets. For example, the distribution of the sum of a large number of variables that do not meet all of the conditions required by the normal - the variables may have fatter tails - still can approach a stable distribution, which can display steep peaks, fat tails, and skews that are not allowed by the normal (Rachev et al. 2011;Voit 2003). The normal is one member of this broader family of stable distributions.

\section{Distribution of returns on stocks and bonds}

We use Ibbotson data for returns on corporate bonds and large capitalization stocks from 1926 to 2011, yielding 85 annual returns. These nominal returns are converted to real values 
using the following formula, where inflation represents the historical annual increase in the CPI index:

$$
r_{t}=\frac{1+\text { nominalReturn }_{t}}{1+\text { inflationRate }_{t}}-1
$$

We use annual returns, rather returns over shorter intervals, in order to describe the distribution of returns for a household that manages its assets according to a life-cycle strategy. The stochastic properties of returns over short intervals of time, which would be relevant for a trader or an active portfolio manager, appear to differ significantly from those of annual returns. ${ }^{4}$

Figures $1 \mathrm{~A}$ and $1 \mathrm{~B}$ show the distribution of annual returns on large-capitalization stocks and bonds from 1926 through 2011. The figures also show the distribution of returns that we would expect if these returns were normally distributed with constant means and variances. The distribution of the actual data has a higher incidence of large negative returns than permitted by the normal distribution. ${ }^{5}$

We model the returns for stocks and bonds as a vector auto-regression (VAR):

$$
\left(\begin{array}{l}
r_{t}^{s} \\
r_{t}^{b}
\end{array}\right)=\left(\begin{array}{l}
m^{s} \\
m^{b}
\end{array}\right)+\sum_{i=1}^{n} \mathbf{M}_{i}\left(\begin{array}{l}
r_{t-i}^{s} \\
r_{t-i}^{b}
\end{array}\right)+\left(\begin{array}{c}
e_{t}^{s} \\
e_{t}^{b}
\end{array}\right)
$$

With this specification, returns tend to revert to their means after disturbances displace them. This reversion in returns does not imply that the values of stocks and bonds revert to their previous trends. After a set of large negative returns, for example, future returns will recover, but the new path for the expected value of assets will tend to run below the expectations established before the disturbances occurred.

\footnotetext{
${ }^{4}$ Returns over much shorter holding periods are prone to volatility clustering, and "co-relationships" among the returns on several assets show tail dependence (Gatheral 2006; Rachev et al. 2011). In GARCH models, estimates of the autocorrelation parameter for volatility are near zero in this set of annual data. Estimates of the "degrees of freedom" parameter exceeds 50 in the multivariate Student t distribution for the joint disturbances from the estimated marginal stable distributions for the returns on stocks and bonds.

${ }^{5}$ Although Pearson's chi squared test at conventional significance levels does not reject the null hypothesis that stock and bond returns are normally distributed, the test also would not reject the null hypothesis that the returns follow a stable distribution with fatter tails.
} 
When the 2-by-2 matrixes $\mathbf{M}$ are zero, the expected return for each of the two assets is the same every year. Consequently, expected returns revert quickly to their means, $m^{s}$ and $m^{b}$, after a disturbance. When the matrixes are not zero, the expected return in any year depends on returns over the last $n$ years. For example, when a disturbance pushes returns well below their means, the dynamics embedded in the matrixes might allow expected returns in subsequent years to oscillate around their means before they eventually return to the their "steady-state" expectation:

$$
\mathrm{E}\left(\begin{array}{c}
r_{t}^{s} \\
r_{t}^{b}
\end{array}\right)=\left(\mathbf{I}-\sum_{i=1}^{n} \mathbf{M}_{i}\right)^{-1}\left(\begin{array}{c}
m^{s} \\
m^{b}
\end{array}\right)
$$

We model the disturbances as stable random variables:

$$
e_{t}=\mathrm{S}(\alpha, \beta, \sigma, \mu)
$$

The stable distribution has four parameters: $\alpha$ governs the shape of the distribution, $\beta$ the skew, $\sigma$ the spread, and $\mu$ the location. ${ }^{6}$ A linear combination of variables from a stable distribution also is a stable random variable with the same shape and skew parameters. This unique property of stable random variables makes them attractive for modeling the returns on assets. When the shape parameter equals 2 , the distribution becomes the normal distribution. ${ }^{7}$ When the value of the shape parameter is less than 2, the resulting stable distribution has a higher peak and fatter tails than the normal distribution. The skew parameter dictates whether the shape of the distribution is skewed toward the lower tail (negative value) or upper tail (positive value).

We estimate three versions of the model for returns. The first is a simple random walk, which constrains the matrixes $\mathbf{M}$ to be zero, and the disturbances to be normal random variables, by constraining the shape parameter to equal 2 . The second allows the means of returns to oscillate over time by releasing the constraint on the matrixes. The last allows for fat tails and skew in the distribution of returns by releasing the constraint on the shape parameter. We also

\footnotetext{
${ }^{6} 0<\alpha \leq 2,-1<\beta \leq 1,0<\sigma$. The characteristic function usually describes this distribution because it lacks closed-form probability distribution functions and cumulative distribution functions, except for a few special cases: $\alpha=2$ (normal distribution), $\alpha=1, \beta=0$ (Cauchy distribution), $\alpha=\frac{1}{2}, \beta=1$ (Levy distribution).

${ }^{7}$ The variance of the normal distribution equals $2 \sigma^{2}$, the mean equals $\mu$, and $\beta$ equals zero.
} 
constrain $\mu$ to be equal zero. We estimate each of these models using maximum likelihood methods. Table 1 shows the estimated values of the parameters.

Figure 2 illustrates the effects of the three models of returns on the distribution of wealth. The figure shows the $5^{\text {th }}, 25^{\text {th }}, 50^{\text {th }}, 75^{\text {th }}$, and $95^{\text {th }}$ percentile of the cumulative value of $\$ 100$ invested in large-capitalization stocks for 50 years. The first bar shows the cumulative values when returns are normally distributed with a constant mean of 7 percent and a constant standard deviation of 20.6 percent. The second bar shows the cumulative values when the VAR uses five lags, and the disturbances are normal variables with a constant standard deviation of 19.8 percent. The third bar shows the cumulative values when stocks follow the same VAR process as above, and the disturbances are stable random variables with constant parameters reported in Table 1. When returns follow a VAR with normal disturbances, there is a lower likelihood of extremely large or extremely small cumulative returns than when returns follow a normal distribution with a constant mean and standard deviation. This is because, under the VAR, returns recover after a series of poor returns. But when returns follow a VAR with disturbances drawn from a stable distribution, cumulative returns are lower on average, and there is a much smaller likelihood of very high cumulative returns. This is because households are more likely to suffer catastrophic losses of wealth from which they do not fully recover.

\section{Optimal consumption and asset allocation}

A household that optimizes its consumption over its lifespan must consider its investment, mortality, and labor market risks. We can examine the effects of different assumptions about the distribution of returns on the household's saving and allocation of assets by comparing the household's optimal choices for each of the three models of returns on assets. We calculate the household's loss of utility if it assumes that returns are normally distributed with a constant mean and standard deviation when returns, in fact, follow some other distribution.

The Model. The household initially comprises two spouses age 20. The couple plans to retire at age 65 after working 45 years. The spouses face population average mortality for the 1990 birth cohort until they attain age 101, when death is certain. Each year, the household chooses its consumption and allocates its wealth between stocks and bonds to maximize its 
lifetime expected utility, taking into account its current salary, current financial wealth, and assumptions for distributions of salaries and returns on financial assets in the future. Neither spouse gains utility from leaving a bequest.

The utility of consumption in year $t$ for the household is the sum of the spouses' individual utilities. The spouses' utilities are identical, constant-relative-risk-aversion functions of each spouse's own consumption and a proportion, $\lambda$, of the other spouse's consumption:

$$
\begin{gathered}
u_{t}^{f}=\frac{\left(c_{t}^{f}+\lambda \cdot c_{t}^{m}\right)^{1-\gamma}}{1-\gamma} \quad \text { and } u_{t}^{m}=\frac{\left(c_{t}^{m}+\lambda \cdot c_{t}^{f}\right)^{1-\gamma}}{1-\gamma} \\
u_{t}^{h}=u_{t}^{f}+u_{t}^{m}
\end{gathered}
$$

The household balances the utility of current consumption against the utility of future consumption, which it finances partly by saving to carry wealth into the future. Each spouse discounts the value of future utility at a constant rate of time preference, $\delta$, and at each spouse's survival rate, $S$. After a spouse dies, the household's utility is the utility of the surviving spouse. Consequently, the household chooses consumption and the allocation of its assets to maximize:

$$
\begin{gathered}
V_{t}^{\text {joint }}\left(W_{t}\right)=\frac{\left(C_{t}^{f}+\lambda \cdot C_{t}^{m}\right)^{1-\gamma}}{1-\gamma}+\frac{\left(C_{t}^{m}+\lambda \cdot C_{t}^{f}\right)^{1-\gamma}}{1-\gamma}+E\left[V_{t+1}^{\text {joint }}\left(\widetilde{W}_{t+1}\right)\right] \cdot \frac{S_{t, t+1}^{\text {joint }}}{1+\delta}+ \\
\left(1-S_{t, t+1}^{f}\right) \cdot E\left[V_{t+1}^{m}\left(\widetilde{W}_{t+1}\right)\right] \cdot \frac{S_{t, t+1}^{m}}{1+\delta}+\left(1-S_{t, t+1}^{m}\right) \cdot E\left[V_{t+1}^{f}\left(\widetilde{W}_{t+1}\right)\right] \cdot \frac{S_{t, t+1}^{f}}{1+\delta}
\end{gathered}
$$

where

$$
V_{t+1}^{f}\left(W_{t+1}\right)=\frac{\left(C_{t+1}^{f}\right)^{1-\gamma}}{1-\gamma}+E\left[V_{t+2}^{f}\left(\widetilde{W}_{t+2}\right)\right] \cdot \frac{S_{t+1, t+2}^{f}}{1+\delta}
$$

Subject to the constraint that wealth cannot be less than zero:

$$
\widetilde{W}_{t+1}=\left(W_{t}+Y_{t}-C_{t}\right) \cdot\left(1+\tilde{r}_{t}\right)>0
$$

Should a spouse die at the end of the year, utility depends on the surviving spouse's valuation of potential future consumption. 
The distribution of earnings. The household earns a salary until it retires at age 65 . We model labor-income uncertainty using model and parameter values in Scholz, Seshadri, and Khitatrakun (2006). The log of household's earnings is

$$
\log e_{j}=\alpha^{i}+\beta_{1} A G E_{j}+\beta_{2} A G E_{j}^{2}+u_{j}
$$

where

$$
u_{j}=\rho u_{j-1}+\varepsilon_{j}
$$

and where $e_{j}$ is the observed earnings of the household $i$ at age $j$ in 1992 dollars; $\alpha^{i}$ is the household specific constant; $A G E_{j}$ is the age of the head of the household; $u_{j}$ is a first-order auto-regression error term; and $\varepsilon_{j}$ is an identically, independently normal random variable with mean equal to zero. ${ }^{8}$ We assume that these errors are independent of the disturbances to the returns on their assets. From age 65, the household receives a Social Security benefit that is a non-linear function of its lifetime earnings. ${ }^{9}$

Solving the model. The distribution of the financial resources available to the household in any year depends on the previous path of consumption chosen by the household. ${ }^{10}$ Consequently, solving the model with recursive, dynamic programming methods is prohibitively demanding. We make two approximations to simplify finding a solution.

First, we approximate the joint distribution of disturbances with a Monte Carlo sample. We draw 100,000 paths of disturbances for earnings, the vector of returns for stocks and bonds, and for mortality covering the household's potential 81 remaining years. The span and densities

\footnotetext{
${ }^{8}$ They report parameter estimates in their Appendix Table A1.The model abstracts from the risk of unemployment. Incorporating the risk of unemployment would greatly complicate the analysis because we would need to both model this source of risk and incorporate social insurance programs and labor supply responses within the family. ${ }^{9}$ We first calculate Average Indexed Monthly Earnings. This equals the average of the highest 35 years of wageindexed earnings. The model is estimated in 2012 dollars, so we increase each year's earnings by an assumed 1.1 percent rate of increase in average earnings. But earnings for years after the year in which the worker turned 60 are not wage indexed. We then calculate Primary Insurance Amount (PIA). This equals 90\% of the first \$767 of AIME, $32 \%$ of the amount AIME exceeds $\$ 767$, up to $\$ 4,624$, and $15 \%$ of AIME in excess of $\$ 4,624$. The PIA is then reduced by $13.33 \%$ to reflect the fact that the individual is retiring at age 65 , two years before his Full Retirement Age. As our calculations are in real dollars, there is no need to apply a cost of living adjustment.

${ }^{10}$ The distribution of financial resources each year depends on the ratio of risky earnings (or Social Security benefits in retirement) to risky wealth. The choice of consumption in previous years alters the mean, variance, and higher moments of the ratio of these random variables for all future years. This feature denies closed-form solutions for the value function and results in a prohibitively large number of calculations to find an optimum numerically.
} 
of these paths represent the joint distribution of the random disturbances before the household at age 20. The optimal plan for consuming earnings and for allocating wealth maximizes the expected value of utility over the domain defined by these paths. Second, we approximate the household's plan for consumption and for allocating its wealth with functions that depend on only 6 parameters each.

The Euler condition implies that the optimal paths of expected utility and consumption at age 20 are smooth, with few inflection points. We approximate the choice of consumption along each Monte Carlo path with the function:

$$
\begin{gathered}
C_{t}(m c)=\alpha(t) \cdot\left(Y_{t}(m c)+W_{t}(m c)\right), m c=1 \ldots 100,000 \\
\alpha(t)=\left(1+\exp \left(\sum_{i=0}^{3} \alpha_{i} \cdot t^{i}\right)\right)^{-1}
\end{gathered}
$$

Consumption is proportional to the sum of current income plus current wealth. This proportion, a function of time, ranges smoothly between zero and 1. Consequently, the function precludes the need to impose the wealth constraint separately. The household is likely to consume much of its income when it is young; less of its income in middle age; and more than its income, drawing against its savings, in retirement.

Similarly, we approximate the household's plan for allocating its wealth. In the conventional life-cycle strategy, the household allocates most of its wealth to stocks when it is young and steadily reduces its allocation to stock as it ages. We specify the proportion of wealth that the household plans to allocate to stocks as a function of the age of the household:

$$
\begin{aligned}
& \omega^{s}(t)=\left(1+\exp \left(\sum_{i=0}^{3} \mu_{i} \cdot t^{i}\right)\right)^{-1} \\
& \omega^{b}(t)=1-\omega^{s}(t)
\end{aligned}
$$

This proportion, by construction, varies between 0 and 1, precluding the need to constrain the household from selling short or from leveraging its savings.

We solve for the household's optimal plan for consuming its income and for allocating its wealth for each of three models for the distribution of the returns on assets that we describe in 
Section 2. The first describes the returns on stocks and bonds as simple random walks, with constant means and variances for all years. The second models returns with a VAR of order 5 combined with normal random disturbances, which are identically, independently distributed over time. This description allows mean returns to vary year by year, and it can allow returns to recover more sharply after large disturbances in ways that can compress the volatility of the household's savings, thereby reducing the risk in the household's wealth. The third models returns with the same VAR combined with disturbances that are independent, identical stable random variables. This description increases the household's risk of experiencing extreme changes in its wealth.

The household's optimal program is conditional on the information it possesses at age 20. As the household ages, it will need to recast its plan as its information changes, making midcourse corrections as it gains information about its earnings and returns. Each year's outcomes alter the distributions of future earnings and returns due to their auto-regressive structures, as applicable. Each year's outcomes also change, for future years, the distributions of the household's ratio of earnings to wealth, a ratio that is important for determining its optimal consumption. Even when earnings and returns match expectations, knowing previous outcomes will shift and compress the household's distribution of financial resources in the future. After learning its first 10 years of earnings, the conditional distributions for the ratio of earnings to wealth for the remainder of the household's life would differ in extent and shape from the unconditional distributions that it used for these future years at age 20.

\section{Results}

Figures 3A and 3B report the household's planned asset allocations by age under the alternative assumptions of normally distributed returns with a time invariant mean, a VAR with normally distributed disturbances, and the VAR with disturbances that follow the stable distribution with fat tails and negative skew. The assumed coefficients of risk aversion are 2 (Figure 3A) and 5 (Figure 3B). We do not show asset allocations prior to age 30 because, in our optimization model, households hold relatively little financial wealth before that age.

When stock and bond returns are normally distributed with constant means, we obtain the standard result that the optimal asset allocation to stocks declines with age. We also obtain the 
standard finding that more risk-tolerant households plan to invest larger proportions of their financial wealth in stocks at all ages.

When returns follow a VAR with normally distributed disturbances, stocks are less risky because periods of poor returns are more likely to be followed by periods of above average returns. As a result, at both assumed coefficients of risk-aversion, households optimally choose to invest larger proportions of their financial assets in stocks at all ages, reflecting the lower risk. $^{11}$

When returns follow the VAR with disturbances drawn from the stable distribution with fat tails and negative skew, the optimal asset allocation to stocks is somewhat less than when returns follow a VAR with normally distributed disturbances. Although the household benefits from the recovery in returns following a period of poor returns, this is offset by the additional risk the household faces as a result of the disturbances being drawn from a stable distribution. For those who are more risk tolerant and accumulate more financial assets, the additional risk is sufficient to result in a lower stock allocation than when returns are normally distributed with a constant mean.

To illustrate, assuming a coefficient of risk-aversion of 5, at age 65, the assumed age of retirement, the optimal stock allocation equals 52 percent when returns are normally distributed with a constant mean, 68 percent when they follow a VAR with normally distributed disturbances, and 55 percent when the follow the VAR with disturbances drawn from the stable distribution. Although these differences in optimal asset allocations are small, they are significant. We also find that the optimal asset allocation is sensitive to other parameter values. For example, we obtain large changes in optimal asset allocation when we make plausible changes to the coefficient of risk aversion or to the equity premium.

When the household incorrectly assumes that 1) returns are normally distributed with a constant mean or 2) returns follow a VAR with normal disturbances, when in fact disturbances follow a VAR with disturbances drawn from a stable distribution, its suboptimal plan for accumulating assets and for allocating those assets reduces its potential lifetime consumption. We calculate asset allocation equivalent consumption (AAEC): the percentage increase in per-

\footnotetext{
${ }^{11}$ Our optimization model shows that when returns follow a VAR, households should hold smaller proportions of their financial assets above age 95. At these very advanced ages, remaining life expectancy is only a few years, and the household derives little benefit from the reversion in long-run returns. The smaller portfolio allocation to stocks reflects somewhat greater average remaining wealth among the VAR households.
} 
period consumption that would leave the household indifferent between 1) receiving a consumption "bonus" and basing its consumption and asset allocation decisions on an incorrect model, and 2) receiving no bonus and basing its decisions on the correct model. Assuming constant relative risk aversion and a coefficient of risk aversion of 2, AAEC is 0.95 percent when the household assumes a normal distribution with a constant mean, and 1.17 percent when it assumes that returns follow a VAR with normal disturbances. We characterize this compensation as modest but significant, representing just over one-sixth of a typical 6 percent employee 401(k) contribution rate.

But when the coefficient of risk aversion is 5, AAEC is only 0.03 and 0.07 percent, respectively. When households are averse to risk, their expected distribution of wealth at age 65 is little affected by mistakenly optimizing their choices for a normal diffusion or VAR with normally distributed disturbances, when returns follow the VAR with stable disturbances. They plan to smooth their income less over their lives and depend relatively strongly on bonds and Social Security to finance post-retirement consumption. As a result, although they consume less while working, they plan to accumulate less wealth and allocate a smaller share of that wealth to stocks. Their consequences of using an incorrect optimal allocation are relatively small.

When households are less averse to risk, their subjective assessments of the distribution of age 65 wealth is little affected by mistakenly assuming that returns follow a VAR with normal disturbances, when in fact they follow a VAR with stable disturbances. But households that mistakenly assume that returns follow a VAR with disturbances drawn from a stable distribution greatly over-estimate the odds of achieving very large amounts of wealth at age 65. They allocate a significant share of their wealth to stocks and save less of their labor-market earnings. On average, they are only somewhat disappointed by the amount of wealth they accumulate by age 65. But the upper tail of the distribution of outcomes is substantially less than anticipated.

\section{Conclusions}

The distribution of returns has a substantial impact on optimal asset allocation but adopting an incorrect asset allocation imposes relatively small costs. When households can depend on Social Security benefits to finance their consumption in retirement, their expected utility generally does not depend very strongly on asset allocation. The majority of households derive most of their lifetime consumption from labor market earnings and Social Security. 
Unless households plan to accumulate a substantial amount of financial assets and invest a substantial share of these assets in stocks, compared with the capitalized value of their Social Security benefits and labor market earnings, choosing even substantially incorrect asset allocations only slightly reduces lifetime utility. 


\section{References}

Bodie, Zvi, Robert C. Merton, and William F. Samuelson. 1992. Labor supply flexibility and portfolio choice in a life-cycle model. Journal of Economic Dynamics and Control 16: 427-449.

Campbell, John Y., Andrew W. Lo, and A. Craig MacKinlay. 1997. The Econometrics of Financial Markets. Princeton.

and Robert J. Shiller. 1998. "Valuation Ratios and the Long-Run Stock Market Outlook.” Journal of Portfolio Management. Winter. pp. 11-26.

Fama, Eugene. 1963. "Mandelbrot and the Stable Paretian Hypothesis.” Journal of Business 36(4): 420-429.

Gatheral, Jim. 2006. The Volatility Surface: A Practitioner’s Guide. Hoboken, NJ: John Wiley \& Sons, Inc.

Horneff, Wolfram J., Raimond Maurer, Olivia S. Mitchell, and Ivica Dus. 2006. “Optimizing the Retirement Portfoilio: Asset Allocation, Annuitization, and Risk Aversion” National Bureau of Economic Research Working Paper No. 12,392.

Horneff, Wolfram J., Raimond Maurer, Olivia S. Mitchell, and Michael Z. Stamos. 2009.

"Asset Allocation and Location Over the Life-Cycle with Investment Linked SurvivalContingent Payouts” Journal of Banking and Finance.

Jagannathan, Ravi and Narayana R. Kocherlakota. 1996. Why Should Older People Invest Less in Stocks than Younger People” Federal Reserve Bank of Minneapolis Quarterly Review Vol. 20. No. 3 Pages 11-23.

Malkiel, Burton G. 2003. A Random Walk Down Wall Street. WW Norton \& Co.

Mandelbrot, Benoit. 1963. “The Variation of Certain Speculative Prices.” Journal of Business. Vol 36, pp. 394-419. and Howard M. Taylor. 1967. "On the Distribution of Stock Price Differences.” Operations Research 15(6): 1057-1062.

Poterba, James, Joshua Rauh, Steven Venti, and David Wise. 2006. Life-cycle asset allocation strategies and the distribution of 401(k) retirement wealth. NBER Working Paper No. 11974, National Bureau of Economic Research, Cambridge, MA. 
Rachev, Svetlozar T., Young Shin Kim, Michele Leonardo Bianchi, and Frank J. Fabozzi. 2011. Financial Models with Levy Processes and Volatility Clustering. Hoboken, NJ: John Wiley \& Sons, Inc.

Rice, John (1995). Mathematical Statistics and Data Analysis (Second ed.). Duxbury Press.

Shiller, Robert J. 1981. “Do Stock Prices Move Too Much To Be Justified By Subsequent Changes in Dividends?” American Economic Review. Vol 71(3), pp. 421-36.

Samuelson, Paul A., "Lifetime Portfolio Selection By Dynamic Stochastic Programming” The Review of Economics and Statistics Vol. 51. Issue 3. Pages 239-246.

Taleb, Nassim Nicholas. 1997. Dynamic Hedging: Managing Vanilla and Exotic Options. Wiley

Voit, Johannes (2003). The Statistical Mechanics of Financial Markets (Texts and Monographs in Physics). Springer-Verlag.

Securities and Exchange Commission. 2012. “Determine Your Risk Tolerance” http://www.sec.gov/investor/pubs/roadmap/risk.htm

Xiong, James X. and Thomas M. Idzorek. 2011. "The Impact of Skewness and Fat Tails on the Asset Allocation Decision.” Financial Analysts Journal 67(2): 23-35. 


\section{Tables and Figures}

Table 1: Estimated VAR Model Coefficients

\begin{tabular}{|c|c|c|}
\hline & VAR & Stable \\
\hline $\mathrm{M}_{1}$ & \multicolumn{2}{|c|}{$[-0.0471,0.2794 ;-0.0822,0.1396]$} \\
\hline $\mathrm{M}_{2}$ & \multicolumn{2}{|c|}{$[-0.1579,-0.1097 ;-0.0381,0.1829]$} \\
\hline $\mathrm{M}_{3}$ & \multicolumn{2}{|c|}{$[-0.0745,0.0331 ; 0.0058,-0.0260]$} \\
\hline $\mathrm{M}_{4}$ & \multicolumn{2}{|c|}{$[-0.1543,0.1019 ; 0.0062,0.0997]$} \\
\hline $\mathrm{M}_{5}$ & \multicolumn{2}{|c|}{$[-0.0434,-0.0881 ; 0.0404,0.0168]$} \\
\hline $\mathrm{m}_{\mathrm{s}}$ & \multicolumn{2}{|c|}{0.0958} \\
\hline $\mathrm{m}_{\mathrm{b}}$ & \multicolumn{2}{|c|}{0.0253} \\
\hline $\begin{array}{l}\text { Variance of Residual } \\
\text { Matrix }\end{array}$ & $\begin{array}{ll}{[0.0387,} & 0.0041 ; \\
0.0041, & 0.0077]\end{array}$ & $\begin{array}{ll}{[0.0379,} & 0.0044 ; \\
0.0044, & 0.0079]\end{array}$ \\
\hline \multicolumn{3}{|l|}{ Stable Parameters } \\
\hline Stock & N/A & $\begin{array}{l}1.8947,-0.6994, \\
0.1310,0.0042)\end{array}$ \\
\hline Bond & N/A & $\begin{array}{l}(2.0000,0.0000, \\
0.0548,-0.0015)\end{array}$ \\
\hline
\end{tabular}

Source: Authors’ calculations 
Figure 1A: Actual and Predicted Distribution of Returns on Large Capitalization Stocks

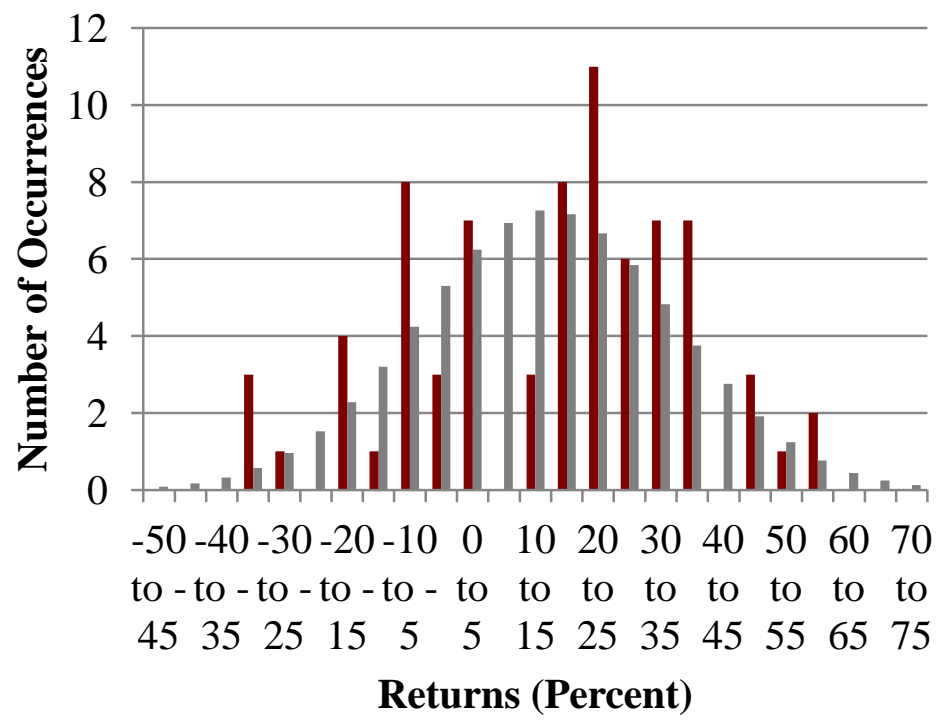

- Actual

Predicted Number of Occurrences if Normally

Distributed

Notes: Authors' calculations. Return data is from Ibbtotson (20??) for 1926-2011.

Figure 1B: Actual and Predicted Returns on Corporate Bonds

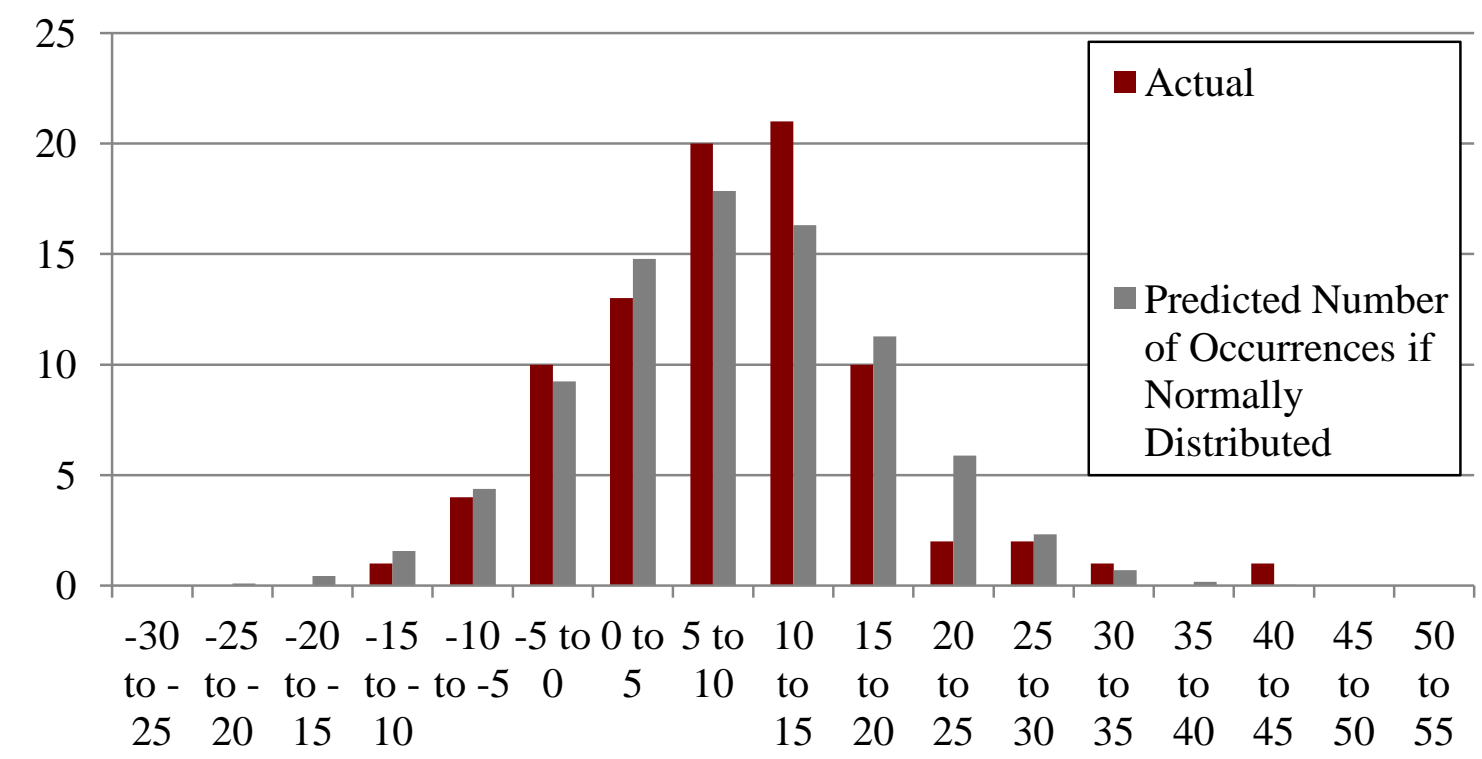

Source: Authors’ calculations. Return data is from Ibbttson (20??) for 1926-2011. 
Figure 2: Value of \$100 After 50 Years of Geometric Returns, By Distribution

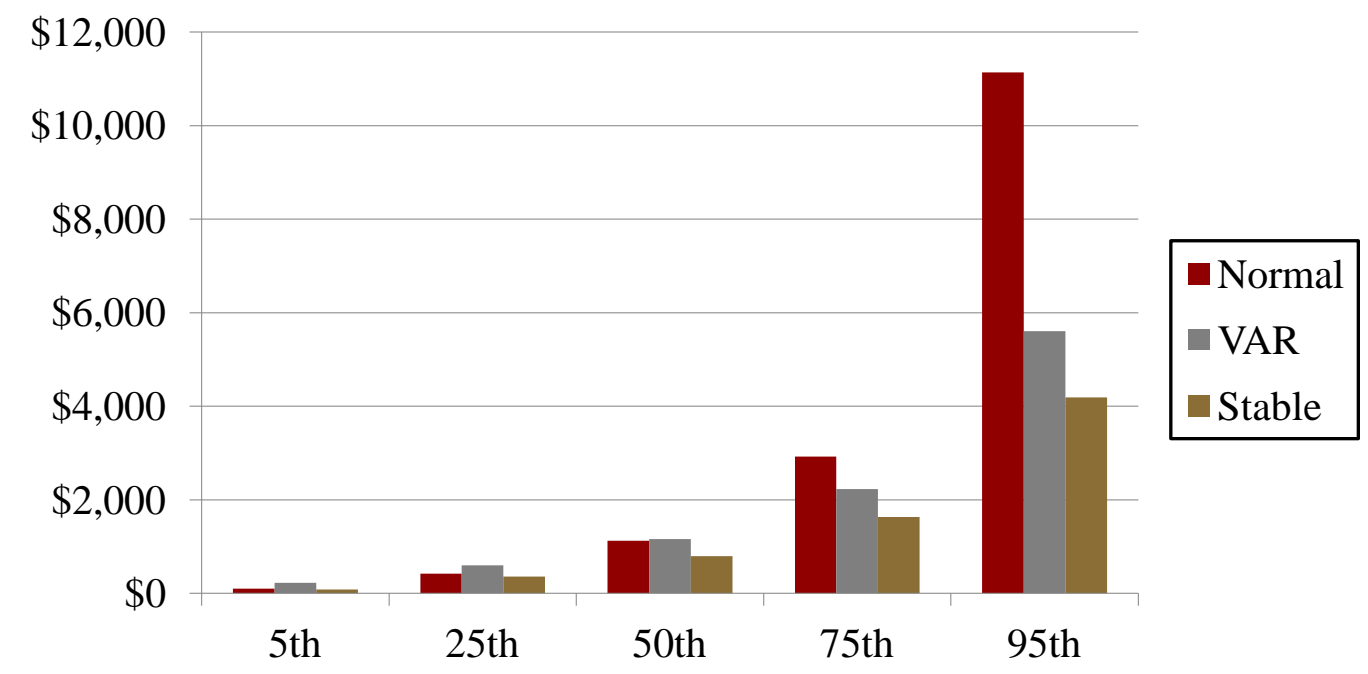

Source: Authors' calculations.

Figure 3A: Optimal Asset Allocation to Stocks - CRRA $=2$

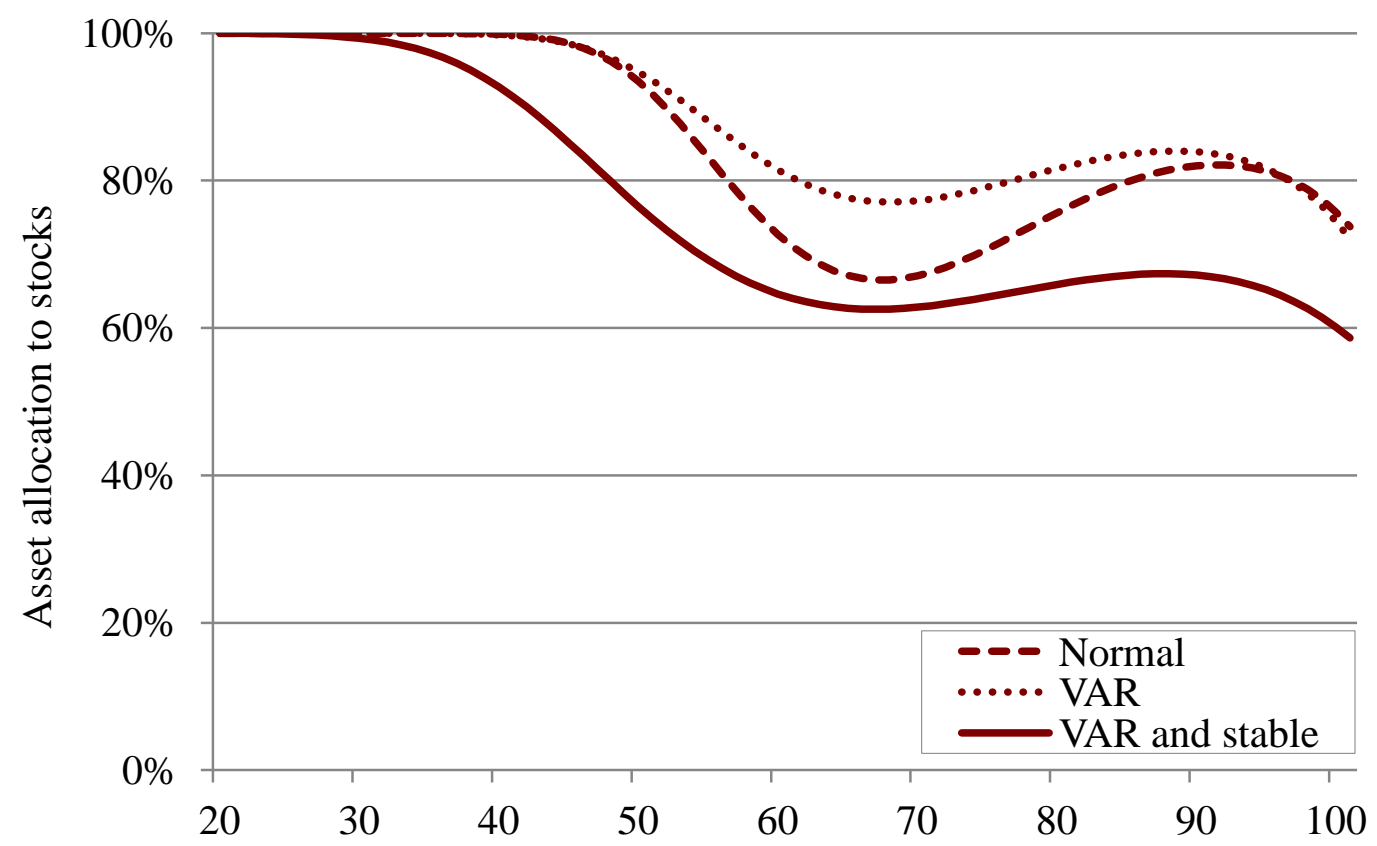

Source: Authors’ calculations 
Figure 3B: Optimal Asset Allocation to Stocks - CRRA $=5$

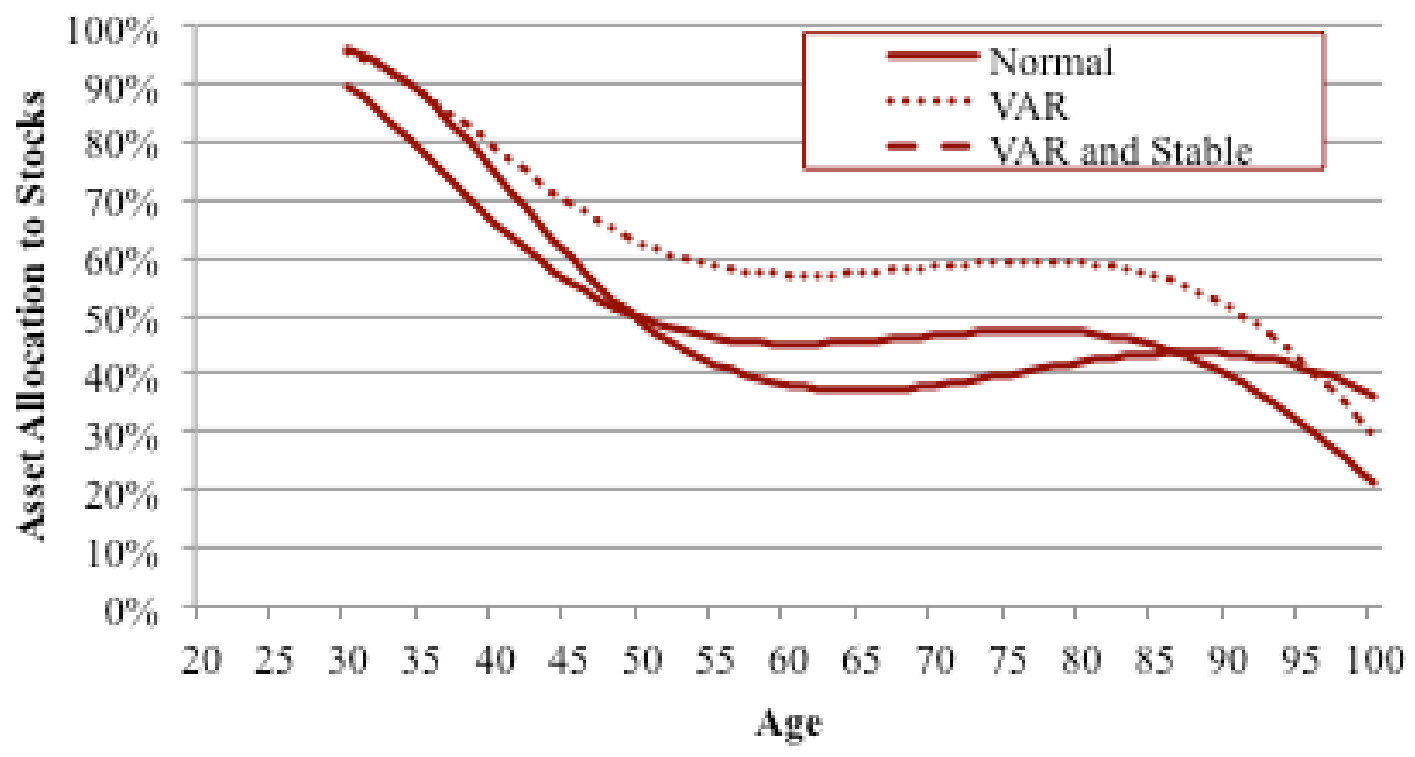

Source: Authors’ calculations. 


\section{RECENT WORKING PAPERS FROM THE CENTER FOR RETIREMENT RESEARCH AT BOSTON COLLEGE}

Employee Mobility and Employer-Provided Retirement Plans

Gopi Shah Goda, Damon Jones, and Colleen Flaherty Manchester, November 2012

Changing Sources of Income among the Aged Population

Barry P. Bosworth and Kathleen Burke, November 2012

Holding Out or Opting Out? Deciding Between Retirement and Disability Applications in Recessions

Matthew S. Rutledge, November 2012

Automatic Enrollment, Employee Compensation, and Retirement Security

Barbara A. Butrica and Nadia S. Karamcheva, November 2012

401(k) Participant Behavior in a Volatile Economy

Barbara A. Butrica and Karen E. Smith, November 2012

Immigrant Networks and the Take-Up of Disability Programs: Evidence from U.S. Census Data

Delia Furtado and Nikolaos Theodoropoulos, October 2012

Growth in Health Consumption and Its Implications for Financing OASDI: An International Perspective

Barry P. Bosworth and Gary Burtless, September 2012

Using Participant Data to Improve 401(k) Asset Allocation

Zhenyu Li and Anthony Webb, September 2012

Job Demand and Early Retirement

Sepideh Modrek and Mark R. Cullen, August 2012

Changes in Labor Force Participation of Older Americans and Their Pension Structures: A Policy Perspective

Frank W. Heiland and Zhe Li, July 2012

How Would GASB Proposals Affect State and Local Pension Reporting?

Alicia H. Munnell, Jean-Pierre Aubry, Joshua Hurwitz and Laura Quinby, June 2012

All working papers are available on the Center for Retirement Research website

(http://crr.bc.edu) and can be requested by e-mail (crr@bc.edu) or phone (617-552-1762). 